\title{
LIDAR OBSERVATIONS OF BIRCH AND SPRUCE POLLEN IN FINLAND
}

\author{
S. Bohlmann ${ }^{1}$, X. Shang ${ }^{1}$, E. Giannakaki ${ }^{1,2}$, M. Filioglou ${ }^{1}$, A. Saarto ${ }^{3}$ and M. Komppula ${ }^{1}$ \\ ${ }^{1}$ Finnish Meteorological Institute, P.O. Box 1627, 70211 Kuopio, Finland \\ ${ }^{2}$ Department of Environmental Physics and Meteorology, University of Athens, 15784 Athens, Greece \\ ${ }^{3}$ Biodiversity Unit of the University of Turku, 20014 University of Turku, Finland \\ *Email: Stephanie.bohlmann@fmi.fi
}

\begin{abstract}
Pollen has various effects on human health and the environment. To understand phenomena behind atmospheric pollen transport and hence improve pollen forecasts, vertically resolved optical properties and geometrical characteristics of the pollen distribution need to be studied. Lidar measurements and especially the particle depolarization ratio have been found to be an excellent tool to track pollen grains. In this study we present first results of atmospheric pollen characterization based on a 11 days period of birch and spruce pollination events.
\end{abstract}

\section{INTRODUCTION}

Pollen is one type of primary biogenic atmospheric aerosol. In addition to the commonly known allergic impact, pollen also has various climatic and environmental impacts [1]. Concentration, types and sources are diverse, making the monitoring of pollen challenging. However, to improve pollen forecasts, the investigation of pollen properties is necessary. Using lidar it is possible to investigate the vertical distribution of aerosols. This information can be used for forecasting pollen concentration, their vertical distribution and transport. Recently lidar measurements have shown a strong depolarization signature caused by non-spherical pollen $[2,3,4,5]$. Thus, in the absence of other depolarizing nonspherical particles, the particle depolarization ratio can be used to track airborne pollen grains. To our knowledge previous studies are only based on single cases or short time periods. Our goal is to improve the existing knowledge of pollen detection using lidar measurements. We conducted a campaign from May to August 2016 at the rural forest station in Vehmasmäki
(Finland) to measure different pollen types throughout the pollination season. Finland provides ideal conditions for the observation of pollen as $86 \%$ of Finland's total area is forestry land. Pine (Pinus sylvestris), spruce (Picea abies), and birch (Betula pubescens, Betula pendula) trees make up $97 \%$ of the growing stock on forest land [6].

During the 4-months campaign, the multiwavelength Raman lidar Polly ${ }^{\mathrm{XT}}$ was simultaneously operated with several in-situ measurements e.g. a Hirst-type volumetric air sampler. 21 different pollen types were detected. In this study we focus on the observation of birch pollen as those are considered to be one of the most allergenic pollen types.

\section{METHODOLOGY}

\subsection{Measurement campaign}

The measurement campaign took place from MayAugust 2016 at Vehmasmäki, Finland (62 $44^{\circ}$ 'N, $27^{\circ} 33^{\prime} \mathrm{E}, 190 \mathrm{~m}$ above sea level); a rural forest site $18 \mathrm{~km}$ from the city center of Kuopio, Eastern Finland. The combination of the multi-wavelength Raman polarization lidar Polly ${ }^{\mathrm{XT}}$ and a Hirst-type pollen sampler enables simultaneous measurements of the vertical aerosol distribution and the pollen concentration on ground. Due to the location of the measurement site, far from major aerosol sources like dust and anthropogenic aerosol, the atmosphere is relatively clean and well suitable for pollen studies.

\subsection{Instrumentation}

Lidar measurements were conducted with the multi-wavelength Raman polarization lidar Polly $^{\mathrm{XT}}[7,8]$. Polly ${ }^{\mathrm{XT}}-$ FMI operates at three 


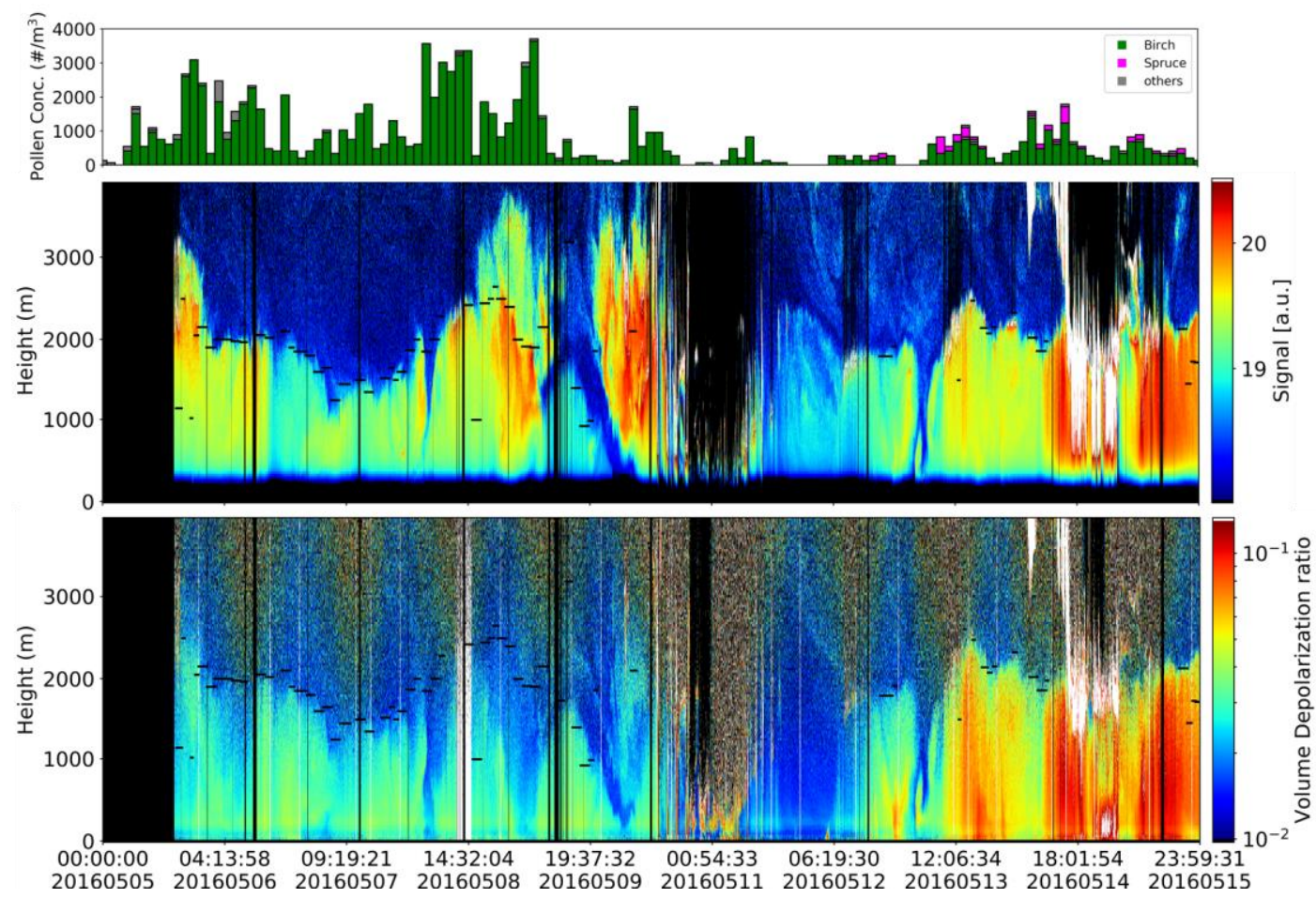

Figure 1 Overview of the 11 days intense birch pollination period. Upper panel: pollen concentration measured with Hirst-type air sampler. Center panel: Range-corrected lidar signal at $1064 \mathrm{~nm}$. Lower panel: Volume depolarization ratio at $532 \mathrm{~nm}$. Black lines indicate top height of the layers used for pollen characterization.

emission wavelengths $(355,532,1064 \mathrm{~nm})$ and seven detection channels. In addition to the three emitted wavelengths, the backscattered signals at the in-elastic Raman shifted wavelengths (387, 407 and $607 \mathrm{~nm}$ ) and the cross-polarized signal at $532 \mathrm{~nm}$ are detected.

A Hirst-type volumetric air sampler located next to the lidar, $4 \mathrm{~m}$ above ground, monitored the pollen concentration. The sampling principle is based on the design described by Hirst [9]. This type of spore sampler enables 7-day collection of pollen grains with 2 hour time resolution.

\section{RESULTS}

Figure 1 shows the temporal evolution of pollen concentration (top panel), range-corrected signal at $1064 \mathrm{~nm}$ (middle panel) and volume depolarization ratio at $532 \mathrm{~nm}$ (lower panel) of the 11 days period from 5 - 15 May. This period has been selected to present the capability of the measurement setup to provide information on different pollen types. According to the pollen concentration measured by the Hirst-type sampler two periods can be defined. During the first period, from 5 - 10 May the measured birch pollen concentration is high and reaches concentrations of up to 3500 pollen grains per cubic meter. During the second period, from 12 - 15 May, a significant amount of spruce pollen mixed with birch was observed. The volume depolarization ratio during this second period is higher, which indicates the increasing presence of non-spherical particles. All lidar measurements with sufficient signal quality and suitable atmospheric conditions were analyzed in 2 hour time intervals to match the pollen collector resolution. From those measurements, layers with high aerosol load were selected using the gradient method [10], and further layers with a distance less than $500 \mathrm{~m}$ from each other were combined to one. For our pollen studies only the lowest layers were considered as those, most likely, contain the highest pollen load. The layer top of the presumed pollen layer is marked with black lines in Fig.1 (middle and lower panel). Mean values of lidar ratio (LR) at $532 \mathrm{~nm}$ (top), backscatter-related Ångström exponent $(\AA)$ at 532/1064 nm (middle) 


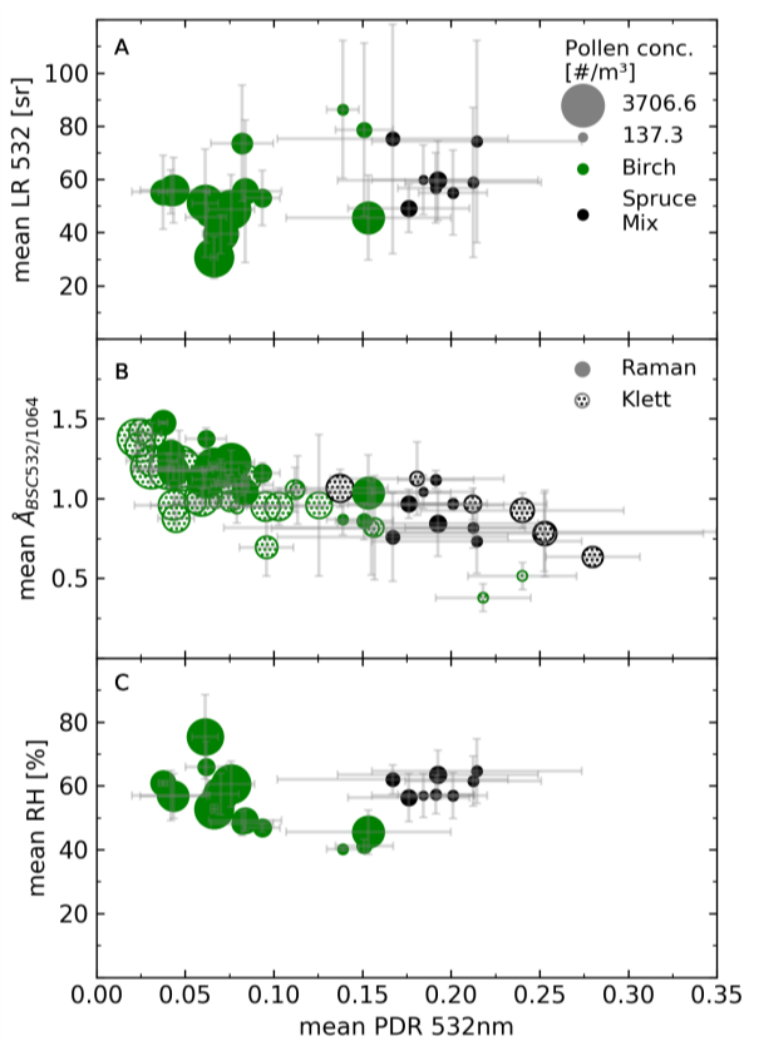

Figure 2 Layer mean values of lidar ratio at 532 nm (top), backscatter-related Angström exponent at 532/1064 $\mathrm{nm}$ (middle) and relative humidity (bottom) against mean PDR at $532 \mathrm{~nm}$. Error bars denote the standard deviation, size the pollen concentration and color the measurement period.

and relative humidity ( $\mathrm{RH}$, bottom) of the defined layers are shown against the particle depolarization ratio (PDR) at $532 \mathrm{~nm}$ in Fig. 2. Error bars denote the standard deviation. Cases marked in green have been measured during the first birch pollen dominated period. During the second period (black dots), birch and spruce pollen have been detected. The lidar ratio ranges in both periods between 20 and $80 \mathrm{sr}$, with a mean lidar ratio of around $55 \mathrm{sr}$ for the birch period and $62 \mathrm{sr}$ for the spruce mixed period. Figure $2 \mathrm{~b}$ shows additionally all day-time measurements using the Klett method. A clear separation of the particle depolarization ratio is visible. Particle depolarization ratio in the second period ranges around $24 \%$ while it is around $10 \%$ during the pure birch period. This higher depolarization is caused by the non-spherical shape of spruce pollen. The Ångström exponent shows a tendency to smaller values with increasing depolarization. The lower Ångström exponent of about 0.8 during the second period is related to the bigger particle size of spruce pollen $(\sim 80 \mu \mathrm{m})$ compared to birch pollen grains $(\sim 20 \mu \mathrm{m})$. An external wetting of the pollen grains at high relative humidity $(>89 \%$ [11]) could change the detected depolarization ratio of the pollen as the shape becomes more spherical. Figure $2 \mathrm{c}$ shows that the relative humidity has no effect on depolarization ratio in the range of our measurements as the measured relative humidity during our campaign is rather low.

\section{CONCLUSION}

Using lidar measurements it is possible to detect pollen grains in the atmosphere. Lidar-derived parameters provide the possibility of identifying different pollen types. In this study, birch and spruce pollen have been detected. Because of their non-spherical shape spruce pollen show a higher depolarization ratio than birch. In upcoming campaigns our dataset will be extended with more case studies and different pollen types, which will allow a more comprehensive characterization of optical pollen properties.

\section{ACKNOWLEDGEMENTS}

This work was supported by the Academy of Finland (project no. 310312).

\section{REFERENCES}

[1] A. L. Steiner et al., Geophys. Res. Lett., 42, 35963602 (2015)

[2] Y. M. Noh et al., Atmos. Chem. Phys., 13, 76197629 (2013)

[3] Y. M. Noh et al., Atmos. Environ., 69, 139-147 (2013)

[4] K. Sassen, Geophys. Res. Lett., 35, L18810 (2008)

[5] M. Sicard et al., Atmos. Chem. Phys., 16, 68056821 (2016)

[6] E. Vaahtera et al., Luonnonvarakeskus (2018)

[7] D. Althausen et al., J. Atmos. Oceanic Technol., 26, 2366-2378 (2009)

[8] R. Engelmann et al., Atmos. Meas. Tech., 9, 17671784 (2016)

[9] J. M. Hirst, Ann. Appl. Biol., 39, 257-265 (1952)

[10] C. Flamant et al., Bound.-Lay. Meteorol, 83, 247284 (1997)

[11] P. T. Griffiths et al., Atmos. Sci. Lett., 13, 289295 (2012) 